\title{
Noninvasive ventilation with helmet versus control strategy in patients with acute respiratory failure: a systematic review and meta-analysis of controlled studies
}

\author{
Qi Liu', Yonghua Gao', Rongchang Chen ${ }^{1 *}$ and Zhe Cheng ${ }^{1 *}$
}

\begin{abstract}
Background: Noninvasive ventilation (NIV) has proved to be a useful technique for breathing support. However, complications, discomfort, and failure of NIV were commonly caused by the mask. Therefore, the helmet was developed to improve performance and reduce complications; however, there has been no conclusive results on its effect until now. Thus, we performed a systematic review and meta-analysis to investigate the effect of NIV with a helmet versus the control strategy in patients with acute respiratory failure (ARF).

Methods: We searched Cochrane Library, PubMed, Ovid, and Embase databases and bibliographies of relevant articles published before June 2016. Randomized and case-control studies that adopted the helmet as an NIV interface and compared it with another interface were included. The primary outcomes were hospital mortality, intubation rate, and complications. The secondary outcomes included the length of intensive care unit (ICU) stay, gas exchange, and respiratory rate. Pooled odds ratios (ORs) and $95 \%$ confidence intervals (Cls) were calculated by the Mantel-Haenszel method and mean difference by the inverse variance method in a fixed effect model or random effects model according to the heterogeneity.

Results: A total of 11 studies involving 621 patients were included. The overall hospital mortality was $17.53 \%$ in the helmet NIV group versus $30.67 \%$ in the control group. Use of the helmet was associated with lower hospital mortality (OR 0.43, $95 \% \mathrm{Cl} 0.26$ to $0.69, p=0.0005)$, intubation rate (OR $0.32,95 \% \mathrm{Cl} 0.21$ to $0.47, P<0.00001)$, and complications ( $\mathrm{OR} 0.6,95 \% \mathrm{Cl} 0.4$ to $0.92, P=0.02$ ). In contrast, there was no significant difference in gas exchange and ICU stay $(P>0.05)$. Subgroup analysis found the helmet reduced mortality mainly in hypoxemic ARF patients $(P<0.05)$ and a lower intubation rate was shown in randomized trials; fewer complications caused by the helmet might be restricted to case-control trials. Additionally, the effect of the helmet on $\mathrm{PaCO}_{2}$ was influenced by type of ARF and ventilation mode $(P<0.00001)$.

Conclusion: NIV with a helmet was associated with reduced hospital mortality and intubation requirement. The helmet was as effective as the mask in gas exchange with no additional advantage. Large randomized controlled trials are needed to provide more robust evidence.
\end{abstract}

Keywords: Helmet, Noninvasive ventilation, Facial mask

(Continued on next page)

\footnotetext{
*Correspondence: qi.liu@vip.163.com; chengzhehi@126.com

${ }^{1}$ Department of Pulmonary and Critical Care Medicine, the First Affiliated

Hospital of Zhengzhou University, 1st Jianshe East Road, Zhengzhou, Henan

450001, People's Republic of China

Full list of author information is available at the end of the article
} 
(Continued from previous page)

Abbreviations: ARF, Acute respiratory failure; $\mathrm{Cl}$, Confidence interval; ICU, Intensive care unit; $\mathrm{MD}$, Mean difference; $\mathrm{NIV}$, Noninvasive ventilation; OR, Odds ratio; $\mathrm{PaCO}_{2}$, Partial pressure of carbon dioxide in arterial blood; $\mathrm{PaO}_{2} /$ $\mathrm{FiO}_{2}$, The ratio of the partial pressure of oxygen in arterial blood to the inspired oxygen fraction; PSV, Pressure support ventilation; RCT, Randomized controlled trial; SD, Standard deviation

\section{Background}

Noninvasive ventilation (NIV) has proved to be a useful technique for breathing support that improved gas exchange and reduced the need for intubation and mortality in patients with exacerbation of chronic obstructive pulmonary disease, acute cardiogenic pulmonary edema, and blunt chest trauma [1-4]. However, the overall failure of NIV occurred in $16-30 \%$ of patients [5, 6], which depended on not only the underlying cause of acute respiratory failure (ARF) and the severity of the patients' disease, but also the multiple technical causes including interface-associated complications $[7,8]$.

The mask turned mechanical ventilation without intubation into reality and was a key success factor in NIV. Despite great improvements in the material quality, shape, size, and fixing system of the mask, complications such as skin lesions, nasal pain, ulcerations of the nose bridge, and discomfort were very common $[7,9,10]$. NIV might fail in $18 \%$ of cases attributable to mask discomfort [11], and failure of facial mask-delivered NIV was associated with a threefold increase in hospital mortality [12]. In an attempt to improve performance and reduce complications, the helmet was developed, which was a new-fashioned interface with the advantage of avoiding skin lesions and improving patient comfort independent of face morphology [13, 14]. Nevertheless, there has been no clear consensus on its effect until now. Whether NIV delivered by helmet could reduce the intubation rate and mortality was still causing controversy $[15,16]$, furthermore, the effect on gas exchange was also confusing. Some studies indicated NIV delivered by helmet could improve oxygenation further compared with a face mask $[17,18]$, while others showed there was no significant difference in oxygenation [19-21], and some studies even demonstrated helmet-induced carbon dioxide rebreathing [22].

Therefore, we conducted a meta-analysis to investigate the effect of NIV with a helmet on hospital mortality, intubation rate, complications, and gas exchange versus the control strategy in patients with ARF.

\section{Methods}

This systematic review and meta-analysis was performed in adherence to the recently published Preferred Reporting Items for Systematic Reviews and Meta-Analyses (PRISMA) statement [23] and our prespecified protocol.
Ethical approval and patient consent were not required since this was a meta-analysis of previously published studies. The eligible participants were adults (at least 18 years old) who suffered from ARF defined by the widely accepted consensus and needed breathing support. Interventions in the experiment group were NIV with a standard or new-generation helmet independent of ventilation mode; breathing support strategies in the control group included NIV or oxygen therapy with any kind of noninvasive interface. The primary outcomes were hospital mortality, intubation rate, and complications. The secondary outcomes included the length of stay in the intensive care unit (ICU), arterial blood gas exchange [including $\mathrm{pH}$, the ratio of arterial oxygen partial pressure to fractional inspired oxygen $\left(\mathrm{PaO}_{2} / \mathrm{FiO}_{2}\right)$, and partial pressure of carbon dioxide in the blood $\left.\left(\mathrm{PaCO}_{2}\right)\right]$ and respiratory rate. Randomized and case-control trials that met the eligible criteria were included, while crossover studies were excluded.

\section{Search strategy}

Two authors (QL and YG) performed a computerized search of the Cochrane Library, PubMed, Ovid, and Embase databases for articles published from inception to June 2016. The search strategy was a combination of keywords and terms as follows: helmet OR hood AND mechanical ventilation $\mathrm{OR}$ noninvasive ventilation $\mathrm{OR}$ oronasal mask OR facial mask OR nasal mask OR oxygen therapy. The searches were restricted to studies on humans without language limitations. The references of all included articles were checked manually to identify additional eligible studies. Duplicate articles were identified and deleted.

\section{Eligibility criteria}

We screened for relevant studies that adopted the standard or new-generation helmet as an interface for breathing support. The inclusion criteria were as follow: (1) the main objective was to compare the effect of helmet ventilation with the control strategy, including randomized controlled trials (RCTs) and case-control studies; (2) adult patients with ARF; (3) outcomes were related to short-term effect such as gas exchange or long-term effect such as hospital mortality; (4) at least one outcome could be extracted. The exclusion criteria were: (1) helmet was introduced for prophylactic use; (2) trial subjects were postoperative 
patients, healthy volunteers, or simulators; (3) only a meeting paper or abstract was published without the full text; (4) studies without a control group; (5) editorials, case reports, letters, reviews, news, comments, guidelines, and meta-analyses. Checking of potentially eligible studies was performed independently by two authors (QL and YG), and in case of disagreement, both authors reviewed the article together until a consensus was made [24] and a third researcher $(\mathrm{ZC})$ decided whether to include it or not.

\section{Data extraction and quality assessment}

General material and outcomes were extracted from the selected articles. For dichotomous data (hospital mortality, intubation rate, and complications), number of events and patients in each group were picked up as the established protocol. For continuous data (gas exchange, respiratory rate, length of stay in ICU), we extracted the means, standard deviations, and the group sizes. The patient who refused intubation when meeting intubation criteria was included in the intubation group, the other data was extracted directly. To assess the possible risk of bias for RCTs, we used the Cochrane Collaboration tool, Table 8.5.a in the Cochrane Handbook for Systematic Reviews of Interventions, for assessing the risk of bias [25]. This tool covered six domains as follows: sequence generation, allocation concealment, blinding of participants and personnel, blinding of outcome assessment, incomplete outcome data, and selective outcome reporting. Each domain was rated as "high risk", "low risk" or "unclear" of bias according to the relative information. To assess the possible risk of bias for case-control trials, we adopted the Newcastle-Ottawa scale (NOS), which focused on three categories: selection, comparability, and exposure with each being awarded a maximum of nine stars on items [26]. The judgements were made independently by two review authors (QL and YG). In case of disagreement, it was resolved first by discussion and then by consulting a third author (ZC) for arbitration.

\section{Statistical analysis}

We performed our meta-analysis including all studies. For dichotomous outcomes, pooled odds ratio (OR) with $95 \%$ confidence interval (CI) was estimated by the Mantel-Haenszel method. For continuous outcomes, pooled effect sizes were calculated by the inverse variance method and expressed as mean difference (MD) with $95 \%$ CI. If the homogeneity across studies was sufficient, the analysis was performed using a fixed effect model, whereas if not, a random effects model was used. The heterogeneity across studies was tested by the $\mathrm{I}^{2}$ statistic, a quantitative measure of inconsistency [27, 28]. $\mathrm{I}^{2}$ values of $25-50 \%$ indicated low, $50-70 \%$ moderate, and $>75 \%$ high heterogeneity [24]. We further conducted subgroup analysis to explore possible explanations for heterogeneity. A $P$ value of less than 0.05 was considered to be statistically significant for all analyses. Potential publication bias was assessed by visual inspection of the funnel plot in which the logarithms of ORs were plotted against their standard errors. Statistical analyses were performed with Review Manager 5.3 software (Cochrane Collaboration, Oxford, UK). We adopted Begg's and Egger's tests to evaluate the publication bias quantitatively and estimated further using a trim and fill method if necessary by STATA 12.0 (Stata Corp, College Station, TX, USA).

\section{Results}

\section{Literature search and study identification}

We found 310 articles according to the electronic search strategy and one additional study was added from the reference list of one article. The identifying process was shown in Fig. 1. A total of 246 studies were excluded according to the inclusion and exclusion criteria after screening titles and abstracts for relevance, patients recruited, and article type. Fifty-four studies were excluded after examination of the full text. Finally, 11 studies involving 621 patients, with six RCTs [15, 16, 29-32] and five case-control studies $[14,17,20,33,34]$, were included for the meta-analysis. These studies recruited patients admitted to ICUs [14, 15, 20, 29-32, 34], emergency departments [33], high dependency units [16], and departments of hematology [17] in different countries: Italy [14-17, 20, 34], Turkey [29, 30], Brazil [31], America [32], and France [33]. The characteristics of the studies are shown in Table 1. Eight studies performed NIV through helmet with pressure support ventilation (PSV) $[14,15,20,29-32,34]$ and three with continuous positive airway pressure (CPAP) $[16,17,29]$. In the control group, the interfaces were facial mask in nine studies [14, 17, 20, 29-34], oronasal mask [15] and Venturi mask [16] in one study, respectively.

\section{Quality assessment}

The results of quality assessment were shown in Table 2 and Table 3. As shown in Table 2, the scores of casecontrol trials ranged from five to eight stars, more than four stars were defined as high-quality. All studies reported the clear definition of cases and controls. All cases in each study were included during a certain period, in certain medical centers, and thus confirm the representativeness of cases. These items were awarded stars. Four historical controlled studies used different methods to ascertain exposure for cases and controls and the samples might be from different population because of inclusion from different periods [17, 20, 33, 34]. In the control group, one study with shorter NIV duration [17] and one with lower pressure support [20], we considered insufficient for additional control factors. No study mentioned the nonresponse rate. All of these 


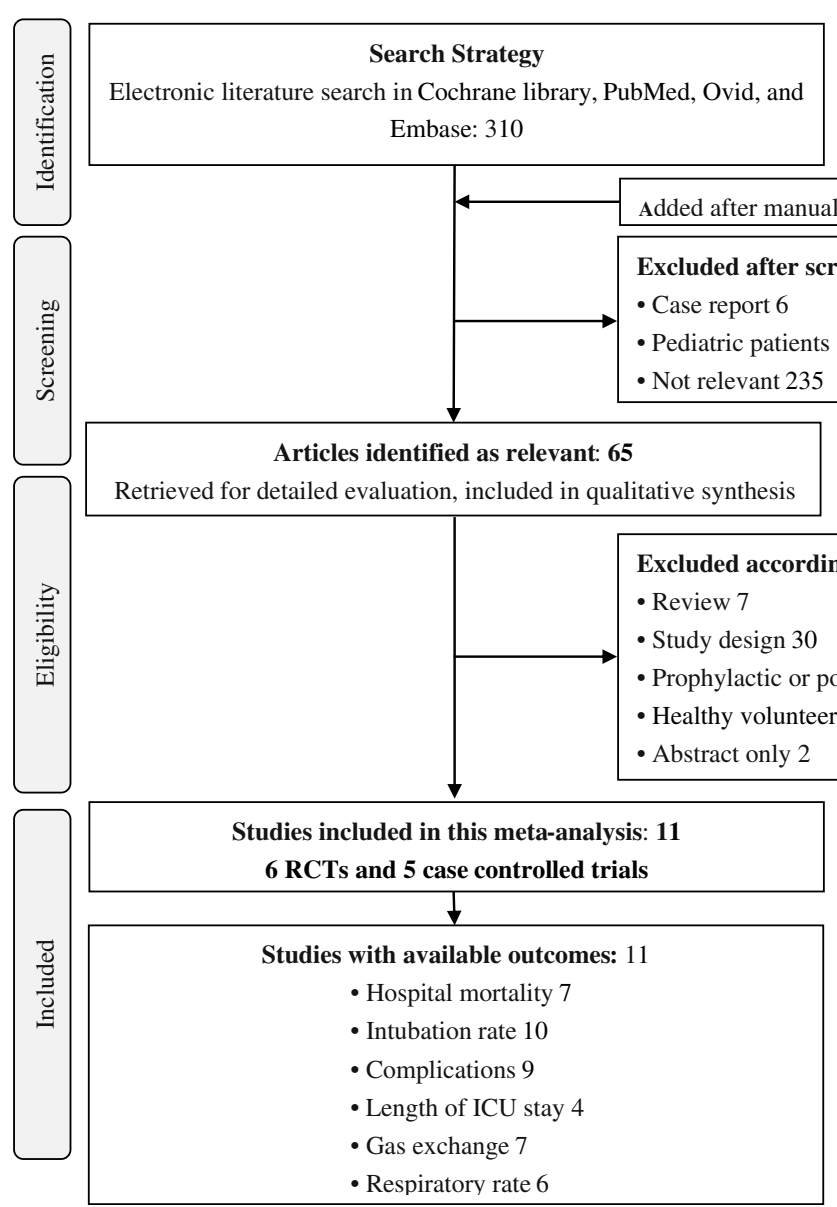

Fig. 1 Flow chart showing the selection of studies in this meta-analysis

conditions were not awarded stars. For the RCTs, as shown in Table 3, most of domains were evaluated as low risk of bias. Most notably, blinding of participants and personnel was not possible in these trials because of the nature of the intervention, i.e., NIV with a helmet or not, therefore performance bias was considered as high risk in all the studies. For the outcomes of interest, such as mortality, the outcome assessment was not affected by blinding or not, we evaluated the detection bias as low risk.

\section{Effect of NIV with a helmet on hospital mortality}

Seven studies including 449 patients reported hospital mortality. The pooled results are shown in Fig. 2a. The hospital mortality was $17.53 \%(37 / 211)$ in the helmet NIV group compared to $30.67 \%(73 / 238)$ in the control group. Pooled results showed the helmet was associated with lower hospital mortality (OR 0.43, 95 \% CI 0.26 to $0.69, P=0.0005)$. There was no heterogeneity found across studies within and between subgroups according to study design.
Effect of NIV with a helmet on intubation rate, complications, and length of ICU stay

Ten studies recruiting 599 patients offered information about intubation. NIV with a helmet significantly reduced the intubation rate $(16.85 \%$ versus $37.26 \%)$ and the OR was 0.32 with a $95 \%$ CI from 0.21 to $0.47(P<0.00001)$, the heterogeneity was low with $\mathrm{I}^{2} 41 \%(P=0.09)$ (Fig. 2b). Overall complications in the helmet NIV group were less than the control group with OR 0.60 (95\% CI from 0.40 to $0.92, P=0.02$ ) (Fig. 2c). Only four articles expressed the data of length of ICU stay in the form of mean \pm standard deviation. NIV with a helmet did not affect the length of ICU stay (MD -1.27, $95 \% \mathrm{CI}$ : -3.12 to $0.58, P=0.18$ ) (Fig. 2d).

\section{Effect of NIV with a helmet on gas exchange and respiratory rate}

NIV with a helmet had the same effect on the improvement of $\mathrm{PaO}_{2} / \mathrm{FiO}_{2}$ and arterial $\mathrm{pH}$ as the control strategy $(P>0.05)$ (Fig. 3a, b). $\mathrm{PaCO}_{2}$ in the helmet NIV group was not higher than the control group, but the heterogeneity 
Table 1 Characteristics of the included studies for helmet ventilation in the meta-analysis

\begin{tabular}{|c|c|c|c|c|c|c|c|}
\hline \multirow[t]{2}{*}{ Study } & \multirow{2}{*}{$\begin{array}{l}\text { Study } \\
\text { design }\end{array}$} & \multirow[t]{2}{*}{ Patients } & \multirow{2}{*}{$\begin{array}{l}\text { Experimental } \\
\text { strategy }\end{array}$} & \multirow{2}{*}{$\begin{array}{l}\text { Control } \\
\text { strategy }\end{array}$} & \multicolumn{2}{|c|}{ Sample size } & \multirow[t]{2}{*}{ Outcomes } \\
\hline & & & & & Helmet & Control & \\
\hline Antonelli 2002 [14] & $\begin{array}{l}\text { Prospective } \\
\text { pilot case } \\
\text { control }\end{array}$ & $\begin{array}{l}\text { Patients with } \\
\text { hypoxemic ARF } \\
\text { without COPD }\end{array}$ & $\begin{array}{l}\text { Helmet } \\
\text { PSV }\end{array}$ & $\begin{array}{l}\text { Facial } \\
\text { mask PSV }\end{array}$ & 33 & 66 & $\begin{array}{l}\text { Gas exchange, respiratory rate, intubation } \\
\text { rate, length of NIV, level of pressure support, } \\
\text { ICU stay and hospital mortality, complications }\end{array}$ \\
\hline Pisani 2015 [15] & $\begin{array}{l}\text { Multicenter } \\
\text { RCT }\end{array}$ & $\begin{array}{l}\text { AECOPD with } \\
\text { hypercapnic ARF }\end{array}$ & $\begin{array}{l}\text { Helmet } \\
\text { PSV }\end{array}$ & $\begin{array}{l}\text { Oronasal } \\
\text { mask PSV }\end{array}$ & 39 & 41 & $\begin{array}{l}\text { Respiratory rate, dysponea score, intubation } \\
\text { rate, level of pressure support, hemodynamics, } \\
\text { complications }\end{array}$ \\
\hline Brambilla 2014 [16] & $\begin{array}{l}\text { Multicenter } \\
\text { RCT }\end{array}$ & $\begin{array}{l}\text { Pneumonia with } \\
\text { hypoxemic ARF }\end{array}$ & $\begin{array}{l}\text { Helmet } \\
\text { CPAP }\end{array}$ & $\begin{array}{l}\text { Venturi } \\
\text { mask Oxygen } \\
\text { therapy }\end{array}$ & 40 & 41 & $\begin{array}{l}\text { Gas exchange }{ }^{a} \text {, intubation rate, hospital stay } \\
\text { and mortality, complications }\end{array}$ \\
\hline Principi 2004 [17] & $\begin{array}{l}\text { Historical } \\
\text { case control }\end{array}$ & $\begin{array}{l}\text { Hematological } \\
\text { malignancy with } \\
\text { hypoxemic ARF }\end{array}$ & $\begin{array}{l}\text { Helmet } \\
\text { CPAP }\end{array}$ & $\begin{array}{l}\text { Facial mask } \\
\text { CPAP }\end{array}$ & 17 & 17 & $\begin{array}{l}\text { Gas exchange, intubation rate, PTS, length } \\
\text { of NIV, complications }\end{array}$ \\
\hline Antonelli 2004 [20] & $\begin{array}{l}\text { Historical } \\
\text { case control }\end{array}$ & $\begin{array}{l}\text { AECOPD with } \\
\text { hypercapnic ARF }\end{array}$ & $\begin{array}{l}\text { Helmet } \\
\text { PSV }\end{array}$ & $\begin{array}{l}\text { Facial } \\
\text { mask PSV }\end{array}$ & 33 & 33 & $\begin{array}{l}\text { Gas exchange, respiratory rate, intubation } \\
\text { rate, length of NIV, level of pressure support, } \\
\text { hemodynamics, ICU stay, ICU and hospital } \\
\text { mortality, complications }\end{array}$ \\
\hline Ali 2011 [29] & $\mathrm{RCT}$ & $\begin{array}{l}\text { AECOPD with } \\
\text { hypercapnic ARF }\end{array}$ & $\begin{array}{l}\text { Helmet } \\
\text { PSV }\end{array}$ & $\begin{array}{l}\text { Facial } \\
\text { mask PSV }\end{array}$ & 15 & 15 & $\begin{array}{l}\text { Gas exchange, respiratory rate, hemodynamics, } \\
\text { ICU stay, PTS, intubation rate, complications }\end{array}$ \\
\hline Özlem 2015 [30] & $\mathrm{RCT}$ & $\begin{array}{l}\text { AECOPD with } \\
\text { hypercapnic ARF }\end{array}$ & $\begin{array}{l}\text { Helmet } \\
\text { PSV }\end{array}$ & $\begin{array}{l}\text { Facial } \\
\text { mask PSV }\end{array}$ & 25 & 23 & $\begin{array}{l}\text { Gas exchange }{ }^{a} \text {, respiratory rate }{ }^{\mathrm{b}}, \text { PTS, } \\
\text { complications, ICU stay }{ }^{\mathrm{b}} \text {, length of NIV, } \\
\text { hospital mortality }\end{array}$ \\
\hline Antonaglia 2011 [31] & $\mathrm{RCT}$ & $\begin{array}{l}\text { AECOPD with } \\
\text { hypercapnic ARF }\end{array}$ & $\begin{array}{l}\text { Helmet } \\
\text { PSV }\end{array}$ & $\begin{array}{l}\text { Facial } \\
\text { mask PSV }\end{array}$ & 20 & 20 & $\begin{array}{l}\text { Gas exchange, respiratory rate }{ }^{\mathrm{b}} \text {, intolerance } \\
\text { to the interface, length of ICU } \text { stay }^{\mathrm{b}} \text {, time of } \\
\text { ventilator assistance }\end{array}$ \\
\hline Patel 2016 [32] & $\mathrm{RCT}$ & ARF due to ARDS & $\begin{array}{l}\text { Helmet } \\
\text { PSV }\end{array}$ & $\begin{array}{l}\text { Facial } \\
\text { mask PSV }\end{array}$ & 44 & 39 & 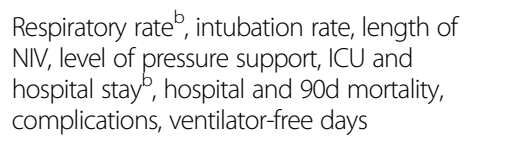 \\
\hline Tonnelier 2003 [33] & $\begin{array}{l}\text { Historical } \\
\text { case control }\end{array}$ & $\begin{array}{l}\text { Cardiogenic } \\
\text { pulmonary edema } \\
\text { with hypoxemic ARF }\end{array}$ & $\begin{array}{l}\text { Helmet } \\
\text { CPAP }\end{array}$ & $\begin{array}{l}\text { Facial } \\
\text { mask CPAP }\end{array}$ & 11 & 11 & $\begin{array}{l}\text { Glasgow coma scale, gas exchange, respiratory } \\
\text { rate, complications, hospital mortality }\end{array}$ \\
\hline Rocco 2004 [34] & $\begin{array}{l}\text { Historical } \\
\text { case control }\end{array}$ & $\begin{array}{l}\text { Immunocompromised } \\
\text { with hypoxemic ARF }\end{array}$ & $\begin{array}{l}\text { Helmet } \\
\text { PSV }\end{array}$ & $\begin{array}{l}\text { Facial } \\
\text { mask PSV }\end{array}$ & 19 & 19 & $\begin{array}{l}\text { Gas exchange, respiratory rate, intubation rate, } \\
\text { length of NIV, level of pressure support, ICU } \\
\text { stay, ICU and hospital mortality, complications }\end{array}$ \\
\hline
\end{tabular}

$A R F$ acute respiratory failure, COPD chronic obstructive pulmonary disease, $P S V$ pressure support ventilation, NIV noninvasive ventilation, ICU intensive care unit, $A E C O P D$ exacerbation of COPD, CPAP continuous positive airway pressure, PTS patient tolerance scale, $R C T$ randomized control trail, $A R D S$ acute respiratory distress syndrome

${ }^{\mathrm{a}}$ Outcome presented in figure form

${ }^{\mathrm{b}}$ Outcome presented as interquartile range

Table 2 Quality assessment of case-control studies included by NOS

\begin{tabular}{|c|c|c|c|c|c|c|c|c|c|c|}
\hline \multirow[t]{2}{*}{ Study, year } & \multicolumn{4}{|l|}{ Selection } & \multicolumn{2}{|c|}{ Comparability } & \multicolumn{3}{|l|}{ Exposure } & \multirow{2}{*}{$\begin{array}{l}\text { Overa } \\
\text { stars }\end{array}$} \\
\hline & $\begin{array}{l}\text { Is the case } \\
\text { definition } \\
\text { adequate? }\end{array}$ & $\begin{array}{l}\text { Representative } \\
\text { of the cases }\end{array}$ & $\begin{array}{l}\text { Selection } \\
\text { of controls }\end{array}$ & $\begin{array}{l}\text { Definition } \\
\text { of controls }\end{array}$ & $\begin{array}{l}\text { Control for } \\
\text { important } \\
\text { factors }\end{array}$ & $\begin{array}{l}\text { Control for } \\
\text { any additional } \\
\text { factor }\end{array}$ & $\begin{array}{l}\text { Ascertainment } \\
\text { of exposure }\end{array}$ & $\begin{array}{l}\text { Same method } \\
\text { of ascertainment } \\
\text { for cases and } \\
\text { controls }\end{array}$ & $\begin{array}{l}\text { Nonresponse } \\
\text { rate }\end{array}$ & \\
\hline Antonelli 2002 [14] & $\star$ & $\star$ & $\star$ & $\star$ & $\star$ & $\star$ & $\star$ & $\star$ & - & 8 \\
\hline Principi 2004 [17] & $\star$ & $\star$ & - & $\star$ & $\star$ & - & $\star$ & - & - & 5 \\
\hline Antonelli 2004 [20] & $\star$ & $\star$ & - & $\star$ & $\star$ & - & $\star$ & - & - & 5 \\
\hline Tonnelier 2003 [33] & $\star$ & $\star$ & - & $\star$ & $\star$ & $\star$ & $\star$ & - & - & 6 \\
\hline Rocco 2004 [34] & $\star$ & $\star$ & - & $\star$ & $\star$ & $\star$ & $\star$ & - & - & 6 \\
\hline
\end{tabular}


Table 3 Quality assessment of RCTs included by the Cochrane Collaboration tool

\begin{tabular}{|c|c|c|c|c|c|c|}
\hline \multirow[t]{2}{*}{ Study, year } & \multicolumn{2}{|l|}{ Selection bias } & \multirow{2}{*}{$\begin{array}{l}\text { Performance bias } \\
\text { Blinding of participants } \\
\text { and personnel }\end{array}$} & \multirow{2}{*}{$\begin{array}{l}\text { Detection bias } \\
\text { Blinding of } \\
\text { outcome assessment }\end{array}$} & \multirow{2}{*}{$\begin{array}{l}\text { Attrition bias } \\
\text { Incomplete outcome } \\
\text { data assessments }\end{array}$} & \multirow{2}{*}{$\begin{array}{l}\text { Reporting bias } \\
\text { Selective reporting }\end{array}$} \\
\hline & $\begin{array}{l}\text { Random sequence } \\
\text { generation }\end{array}$ & $\begin{array}{l}\text { Allocation } \\
\text { concealment }\end{array}$ & & & & \\
\hline Pisani 2015 [15] & Low & Low & High & Low & Low & Low \\
\hline Brambilla 2014 [16] & Low & Low & High & Low & Low & Low \\
\hline Ali 2011 [29] & Unclear & Unclear & High & High & Low & Low \\
\hline Özlem 2015 [30] & Unclear & Unclear & High & High & Low & Low \\
\hline Antonaglia 2011 [31] & Low & Low & High & High & Unclear & Low \\
\hline Patel 2016 [32] & Low & Low & High & Low & Low & Low \\
\hline
\end{tabular}

Low low risk of bias, High high risk of bias, Unclear unclear risk of bias according to the relative information

was not perfect with $\mathrm{I}^{2}$ equal to $72 \%(P=0.11)$ (Fig. 3c). The respiratory rate was similar in both groups and $\mathrm{MD}$ was -0.59 (95 \% CI: -1.68 to $0.51, P=0.29$ ) (Fig. $3 \mathrm{~d}$ ).

\section{Subgroup analysis}

Trials both designed in randomization and case-control, showed use of a helmet was associated with lower hospitality mortality (Fig. 2). As shown in Table 4, further subgroup analysis according to the type of ARF found that NIV with a helmet reduced mortality mainly in the patient group with hypoxemic ARF with OR 0.38 (0.22, $0.65)(P=0.0005)$, and helmet with both CPAP and PSV could reduce mortality $(P<0.05)$. NIV with a helmet could decrease the intubation in both hypercapnic and hypoxemic ARF patients independent of the ventilation mode $(P<0.05)$. Fewer complications occurred in the subgroup patients with hypercapnic ARF $(P<0.05)$. $\mathrm{PaCO}_{2}$ could be decreased further in hypercapnic patients or ventilation with PSV $(P<0.00001)$, the effect of a helmet on the continuous outcomes (the ICU stay, oxygenation, $\mathrm{pH}$, and respiratory rate) were not influenced by type of ARF and ventilation mode, a helmet improved $\mathrm{pH}$ mainly shown by case-control trials $(P=0.04)$ (Table 5$)$, in addition interfaces used in the control group did not affect the final result significantly (Tables 4 and 5).

\section{Publication bias}

Visual inspection of the funnel plot indicated a little asymmetry for the effect of NIV with a helmet on hospital mortality (Fig. 4). The publication bias was significant when estimated by Egger's test $(P=0.014)$ and was not consistent when estimated by Begg's test $(P=0.072)$. Nevertheless, the pooled results, tested further via trim and fill method, were credible and steady.

\section{Discussion}

To our knowledge, this is the first meta-analysis to investigate the effect of NIV with a helmet on ARF patients. We found that NIV with a helmet significantly reduced hospital mortality, tracheal intubation rate, and complications compared with the control techniques.
And subgroup analyses found NIV with a helmet, especially in PSV mode, could decrease the $\mathrm{PaCO}_{2}$ in hypercapnic patients, but did not increase $\mathrm{PaCO}_{2}$ in the overall group. The helmet was as efficient as a mask on shortening the length of ICU stay, improving oxygenation and $\mathrm{pH}$.

NIV delivered breathing support without the use of endotracheal or tracheostomy tube. The interface between the patients and NIV ventilators included nasal, oronasal, and facial mask. These noninvasive interfaces differentiated NIV from invasive mechanical ventilation, and maintained the airway protection mechanisms and the patient's ability to swallow. Well- cooperated NIV decreased mortality in selected patients [1, 2, 35-37]. However, patient discomfort and complications might limit continuous application of NIV [7], further decrease its efficacy, and even increase mortality. Some of these complications and discomfort were related to the mask $[7-9,38]$. In order to improve tolerability for patients, a transparent helmet made from latex-free polyvinyl chloride was developed [13].

This meta-analysis has shown NIV with a helmet reduced hospital mortality further compared with other masks in both RCTs and case-control trials, which meant the helmet itself had an effect on the patient's survival. This effect might be attributed to the unique advantages that masks did not possess. First, the helmet allowed patients to freely drink, communicate and expectorate. It improved clearance of sputum and collaboration with caregivers without interference of the NIV. Second, the helmet was a better tolerated interface, patients need not try hard to cater to the interface as with a mask. The patient tolerance scale in the helmet group was remarkably higher than in the facial mask control group [14, 17, 29, 39]. Better tolerance allowed a longer continuous application $[14,31]$ and increased the success rate of NIV [40]. In fact, no patients failed NIV as a result of claustrophobia, discomfort, or pain related to a helmet while $38 \%$ patients might have a failed NIV owing to a mask [14], which would increase hospital mortality. Third, the helmet could be applied to any 


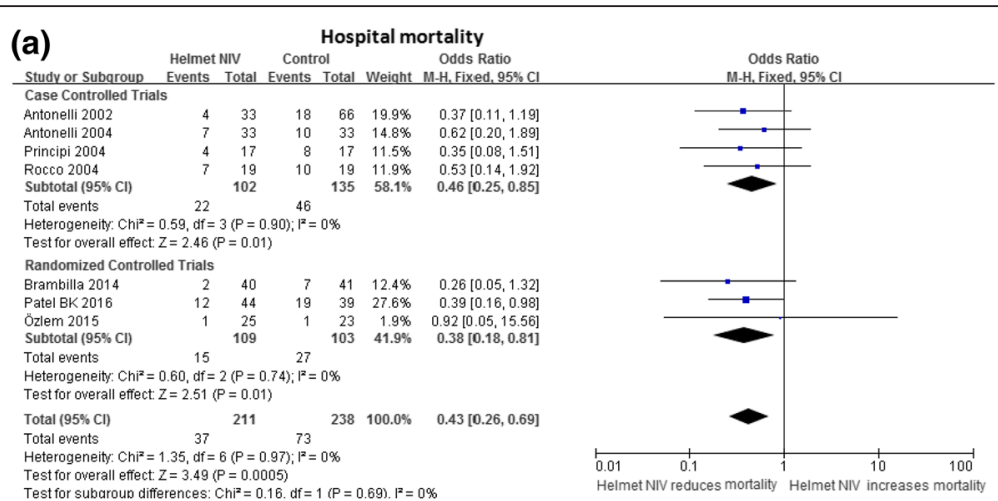

\section{(b)}

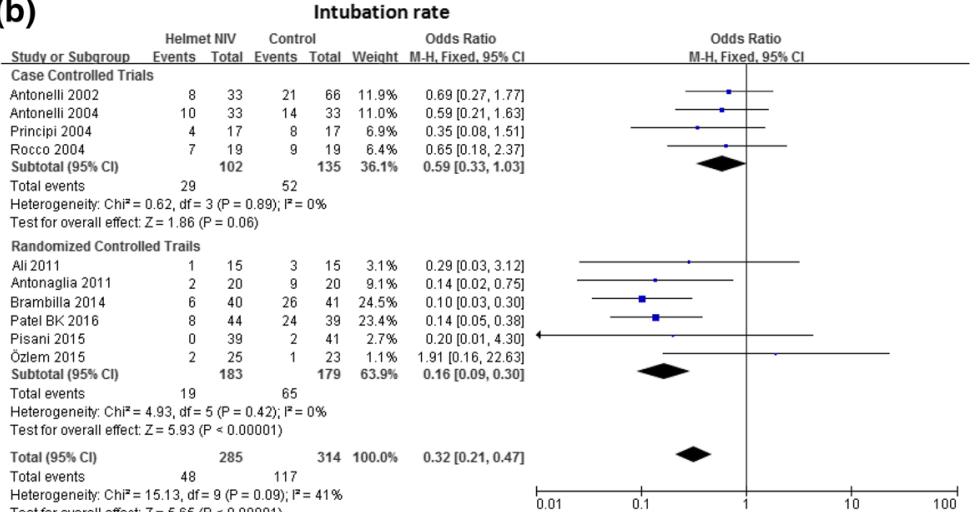
Total events,$C^{2}=15.13$, df $=9(P=0.09) ; F^{2}=41 \%$
Test for overerall effect $Z=5.65(P<0.00001)$

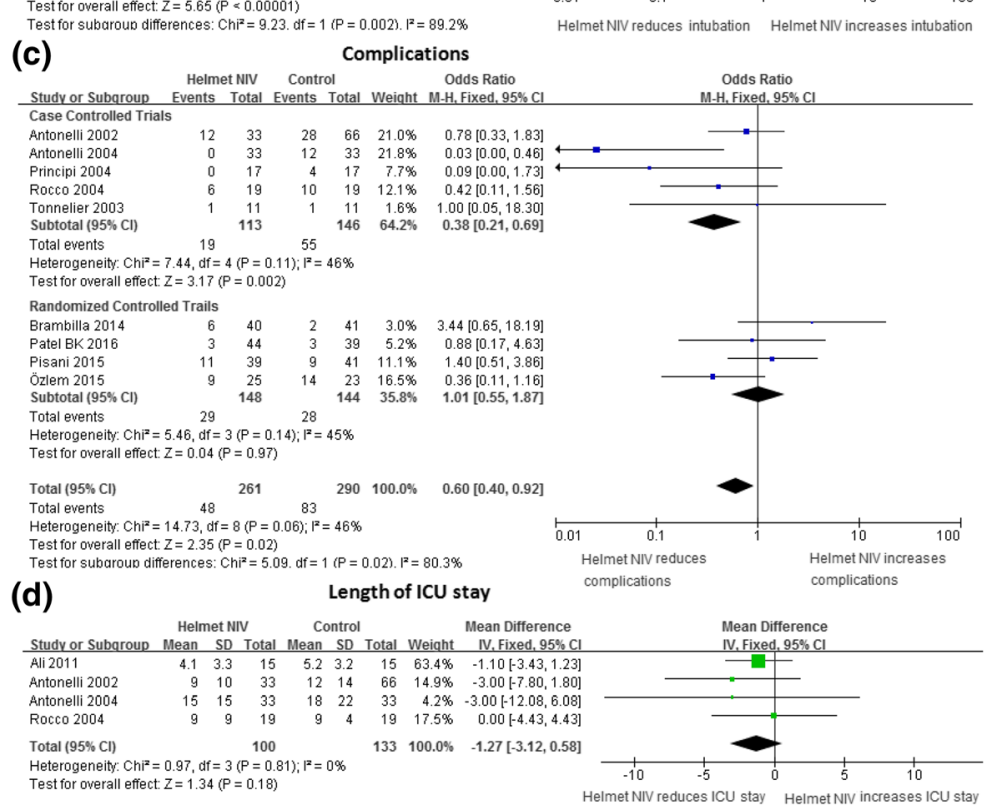

Fig. 2 Effect of NIV with a helmet on primary outcomes and length of ICU stay. The helmet NIV group represents patients receiving NIV with a helmet, the control group represent patients receiving NIV with a mask or oxygen therapy with a mask. Vertical solid line null effect, boxes and horizontal lines outcome in the corresponding study and $95 \% \mathrm{Cl}$, filled rhombic boxes overall effect size. a Effect of NIV with a helmet on hospital mortality; $\mathbf{b}$ effect of NIV with a helmet on intubation rate; $\mathbf{c}$ effect of NIV with a helmet on complications; $\mathbf{d}$ effect of NIV with a helmet on length of ICU stay. Cl confidence interval, ICU intensive care unit, IV inverse variance method, NIV noninvasive ventilation, M-H Mantel-Haenszel method, SD standard deviation

patient regardless of their face contour. During the course of NIV with a mask, 24-64\% of patients had to change to another type of mask $[12,41]$ and the most common reason for non-adaptation to the mask was the shape of the face $[41,42]$. Unlike the mask, the helmet could also be used in difficult anatomical situations such 


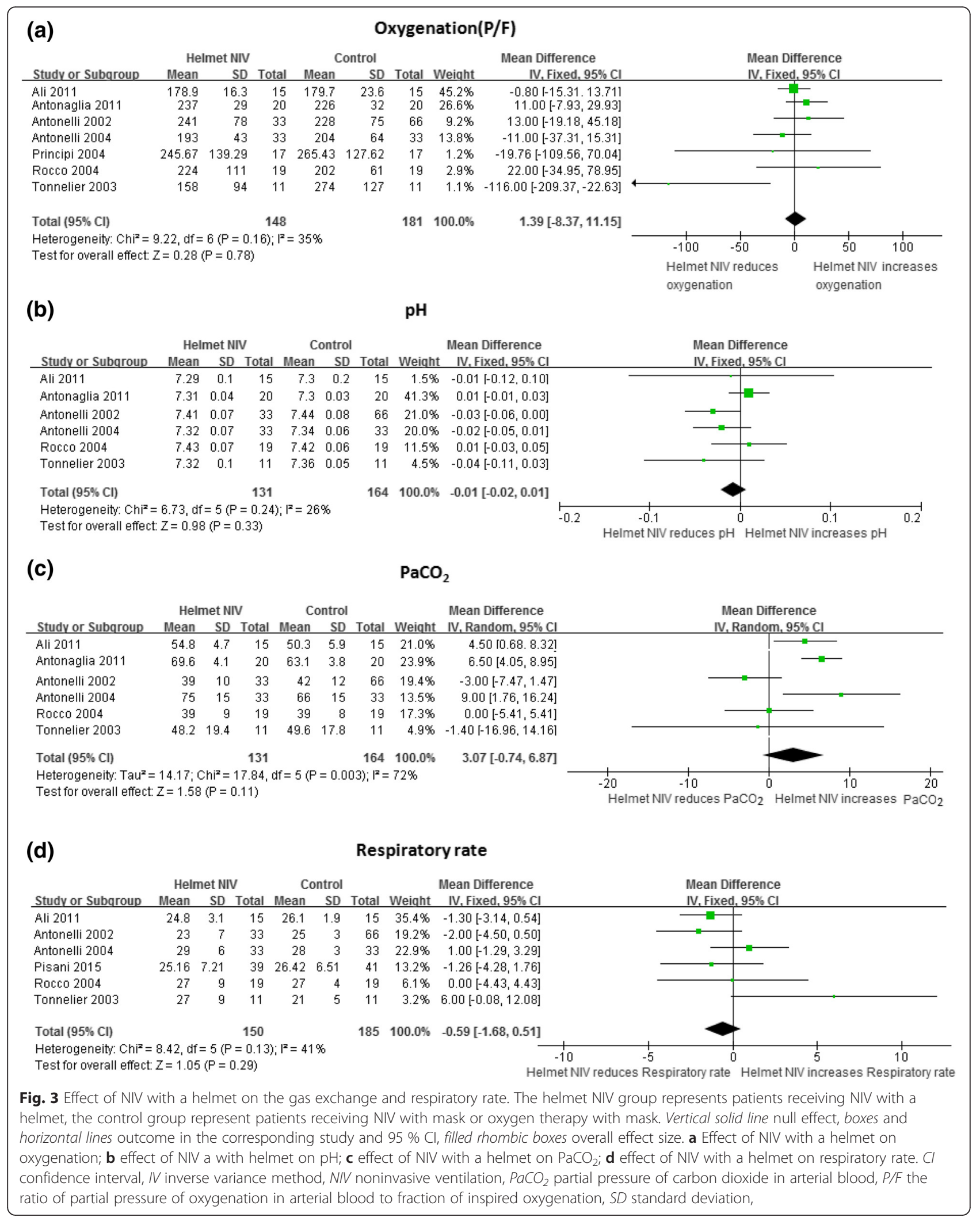


Table 4 Subgroup analysis - the effect on primary outcomes

\begin{tabular}{|c|c|c|c|c|c|c|c|}
\hline & $\begin{array}{l}\text { No. of } \\
\text { studies }\end{array}$ & $\begin{array}{l}\text { Helmet NIV } \\
\text { event/total }\end{array}$ & $\begin{array}{l}\text { Control } \\
\text { event/total }\end{array}$ & $1^{2}(\%)$ & $\begin{array}{l}P \text { value for } \\
\text { heterogeneity }\end{array}$ & OR $95 \%$ Cl & $\begin{array}{l}\text { Overall effect } \\
Z / P \text { value }\end{array}$ \\
\hline \multicolumn{8}{|l|}{ Hospital mortality } \\
\hline \multicolumn{8}{|l|}{ Type of ARF } \\
\hline Hypercapnic & 2 & $8 / 58$ & $11 / 56$ & 0 & 0.8 & $0.65[0.28,2.06]$ & $0.81 / 0.42$ \\
\hline Hypoxemic & 5 & $29 / 153$ & $62 / 182$ & 0 & 0.97 & $0.38[0.22,0.65]$ & $3.49 / 0.0005$ \\
\hline \multicolumn{8}{|c|}{ Ventilation mode in the experimental group } \\
\hline CPAP & 2 & $6 / 57$ & $15 / 58$ & 0 & 0.79 & $0.30[0.10,0.89]$ & $2.17 / 0.03$ \\
\hline PSV & 5 & $31 / 154$ & $58 / 180$ & 0 & 0.77 & $0.46[0.27,0.79]$ & $2.8 / 0.005$ \\
\hline \multicolumn{8}{|c|}{ Interfaces used in the control group } \\
\hline Facial mask & 6 & $35 / 171$ & $66 / 197$ & 0 & 0.97 & $0.45[0.27,0.74]$ & $3.12 / 0.002$ \\
\hline Venturi mask & 1 & $2 / 40$ & $7 / 41$ & NA & NA & $0.26[0.05,1.32]$ & $1.63 / 0.1$ \\
\hline \multicolumn{8}{|l|}{ Intubation rate } \\
\hline \multicolumn{8}{|l|}{ Type of ARF } \\
\hline Hypercapnic & 5 & $15 / 132$ & $29 / 132$ & 0 & 0.42 & $0.42[0.20,0.85]$ & $2.41 / 0.02$ \\
\hline Hypoxemic & 5 & $33 / 153$ & $88 / 143$ & 61 & 0.03 & $0.28[0.17,0.45]$ & $5.16 /<0.0001$ \\
\hline \multicolumn{8}{|c|}{ Ventilation mode in the experimental group } \\
\hline CPAP & 2 & $10 / 57$ & $34 / 58$ & 42 & 0.19 & $0.16[0.07,0.36]$ & $4.28 /<0.0001$ \\
\hline PSV & 8 & $38 / 228$ & $83 / 256$ & 30 & 0.19 & $0.39[0.25,0.62]$ & $4.05 /<0.0001$ \\
\hline \multicolumn{8}{|c|}{ Interfaces used in the control group } \\
\hline Facial mask & 8 & $42 / 206$ & $89 / 232$ & 29 & 0.2 & $0.39[0.25,0.61]$ & $4.16 /<0.0001$ \\
\hline Oronasal mask & 1 & $0 / 39$ & $2 / 41$ & NA & NA & $0.20[0.01,4.30]$ & $1.03 / 0.3$ \\
\hline Venturi mask & 1 & $6 / 40$ & $26 / 41$ & NA & NA & $0.32[0.21,0.47]$ & $5.56 /<0.0001$ \\
\hline \multicolumn{8}{|l|}{ Complications } \\
\hline \multicolumn{8}{|l|}{ Type of ARF } \\
\hline Hypercapnic & 3 & 20/97 & $35 / 97$ & 77 & 0.01 & $0.45[0.23,0.86]$ & $2.42 / 0.02$ \\
\hline Hypoxemic & 6 & $28 / 164$ & $48 / 193$ & 17 & 0.30 & $0.76[0.43,1.32]$ & $0.98 / 0.33$ \\
\hline \multicolumn{8}{|c|}{ Ventilation mode in the experimental group } \\
\hline CPAP & 3 & $7 / 68$ & $7 / 69$ & 57 & 0.10 & $1.01[0.36,2.89]$ & $0.03 / 0.98$ \\
\hline PSV & 6 & $41 / 193$ & $76 / 221$ & 46 & 0.10 & $0.55[0.34,0.87]$ & $2.35 / 0.06$ \\
\hline \multicolumn{8}{|c|}{ Interfaces used in the control group } \\
\hline Facial mask & 7 & $31 / 182$ & $72 / 208$ & 25 & 0.24 & $0.40[0.24,0.67]$ & $3.49 / 0.0005$ \\
\hline Oronasal mask & 1 & $11 / 39$ & $9 / 41$ & NA & NA & $1.40[0.51,3.86]$ & $0.64 / 0.52$ \\
\hline Venturi mask & 1 & $6 / 40$ & $2 / 41$ & NA & NA & $3.44[0.65,18.2]$ & $1.45 / 0.15$ \\
\hline
\end{tabular}

NIV noninvasive ventilation, $O R$ odds ratio, $C l$ confidence interval, $A R F$ acute respiratory failure, CPAP continuous positive airway pressure, $P S V$ pressure support ventilation, $N A$ not applicable

as in edentulous or facial trauma patients [13]. In short, good amenity, better tolerance, and universal application of the helmet ensured NIV was better used and reduced intubation (as shown in this analysis in Fig. 2b), which might contribute to preventing ventilator-associated pneumonia and decreasing hospital mortality [43].

An exciting finding was that the helmet could reduce the mortality of patients with hypoxemic ARF. Some studies aimed to explore applying NIV through a mask in this kind of patient, however, the results were disappointing, successful treatment was lower with a limited effect on the prognosis [43-46]. This might be relevant to the different breathing patterns in hypoxemic ARF and hypercapnic ARF patients. In patients with hypoxemic ARF, mouth breathing was more common, with unavoidable air leaks although a facial or whole face mask was used [47]. The helmet improved tolerance and increased efficient ventilation, which was very important for patients with hypoxemic ARF. The continuous application of NIV was crucial in the onset phases of ARF, which otherwise might 
Table 5 Subgroup analysis - the effect on secondary outcomes

\begin{tabular}{|c|c|c|c|c|c|c|}
\hline & No. of studies & Patients (n) $H / C$ & $I^{2}(\%)$ & $P$ value for heterogeneity & MD $95 \% \mathrm{Cl}$ & Overall effect $Z / P$ value \\
\hline \multicolumn{7}{|l|}{ Length of ICU stay } \\
\hline \multicolumn{7}{|l|}{ Type of ARF } \\
\hline Hypercapnic & 2 & $48 / 48$ & 0 & 0.69 & $-1.22[-3.47,1.04]$ & $1.06 / 0.29$ \\
\hline Hypoxemic & 2 & $52 / 85$ & 0 & 0.37 & $-1.38[-4.63,1.88]$ & $0.83 / 0.41$ \\
\hline \multicolumn{7}{|c|}{ Ventilation mode in the experimental group } \\
\hline CPAP & 1 & $15 / 15$ & NA & NA & $-1.10[-3.43,1.23]$ & $0.93 / 0.35$ \\
\hline PSV & 3 & $85 / 118$ & 0 & 0.63 & $-1.56[-4.63,1.50]$ & $1 / 0.32$ \\
\hline \multicolumn{7}{|l|}{ Study design } \\
\hline Case-control trial & 3 & $85 / 118$ & 0 & 0.63 & $-1.56[-4.63,1.50]$ & $1 / 0.32$ \\
\hline $\mathrm{RCT}$ & 1 & $15 / 15$ & NA & NA & $-1.10[-3.43,1.23]$ & $0.93 / 0.35$ \\
\hline \multicolumn{7}{|c|}{ Oxygenation $\left(\mathrm{PaO}_{2} / \mathrm{FiO}_{2}\right)$} \\
\hline \multicolumn{7}{|l|}{ Type of ARF } \\
\hline Hypercapnic & 3 & $68 / 68$ & 0 & 0.38 & $1.23[-9.32,11.78]$ & $0.23 / 0.38$ \\
\hline Hypoxemic & 4 & $80 / 113$ & 59 & 0.06 & $2.37[-23.34,28.08]$ & $0.18 / 0.86$ \\
\hline \multicolumn{7}{|c|}{ Ventilation mode in the experimental group } \\
\hline CPAP & 2 & $28 / 28$ & 53 & 0.15 & $-66.01[-130.73,-1.28]$ & $2 / 0.05$ \\
\hline PSV & 5 & $120 / 153$ & 0 & 0.59 & $2.96[-6.91,12.83]$ & $0.59 / 0.56$ \\
\hline \multicolumn{7}{|l|}{ Study design } \\
\hline Case-control trial & 5 & $113 / 146$ & 49 & 0.1 & $4.16[-22.55,14.22]$ & $0.44 / 0.66$ \\
\hline $\mathrm{RCT}$ & 2 & $35 / 35$ & 0 & 0.33 & $3.57[-7.95,15.09]$ & $0.61 / 0.54$ \\
\hline \multicolumn{7}{|l|}{$\mathrm{pH}$} \\
\hline \multicolumn{7}{|l|}{ Type of ARF } \\
\hline Hypercapnic & 3 & $68 / 68$ & 16 & 0.3 & $-0.00[-0.02,0.02]$ & $0.01 / 1$ \\
\hline Hypoxemic & 3 & $63 / 96$ & 28 & 0.25 & $-0.02[-0.04,0.00]$ & $1.59 / 0.11$ \\
\hline \multicolumn{7}{|c|}{ Ventilation mode in the experimental group } \\
\hline CPAP & 1 & $11 / 11$ & NA & NA & $-0.04[-0.11,0.03]$ & $1.19 / 0.24$ \\
\hline PSV & 5 & $120 / 153$ & 30 & 0.22 & $-0.01[-0.02,0.01]$ & $0.74 / 0.46$ \\
\hline \multicolumn{7}{|l|}{ Study design } \\
\hline Case-control trial & 4 & $96 / 129$ & 0 & 0.43 & $-0.02[-0.04,-0.00]$ & $2.02 / 0.04$ \\
\hline $\mathrm{RCT}$ & 2 & $35 / 35$ & 0 & 0.73 & $0.01[-0.01,0.03]$ & $0.85 / 0.4$ \\
\hline \multicolumn{7}{|l|}{$\mathrm{PaCO}_{2}$} \\
\hline \multicolumn{7}{|l|}{ Type of ARF } \\
\hline Hypercapnic & 3 & $68 / 68$ & 0 & 0.5 & $6.15[4.17,8.13]$ & $6.08 /<0.00001$ \\
\hline Hypoxemic & 3 & $63 / 96$ & 0 & 0.7 & $-1.76[-5.13,1.60]$ & $1.03 / 0.30$ \\
\hline \multicolumn{7}{|c|}{ Ventilation mode in the experimental group } \\
\hline CPAP & 1 & $11 / 11$ & NA & NA & $-1.40[-16.96,14.16]$ & $0.18 / 0.86$ \\
\hline PSV & 5 & $120 / 153$ & 77 & 0.002 & $4.18[2.46,5.90]$ & $4.76 /<0.00001$ \\
\hline \multicolumn{7}{|l|}{ Study design } \\
\hline Case-control trial & 4 & $96 / 129$ & 61 & 0.05 & $0.15[-2.90,3.20]$ & $0.1 /<0.92$ \\
\hline $\mathrm{RCT}$ & 2 & $35 / 35$ & 0 & 0.39 & $5.92[3.85,7.98]$ & $5.62 /<0.00001$ \\
\hline \multicolumn{7}{|l|}{ Respiratory rate } \\
\hline \multicolumn{7}{|l|}{ Type of ARF } \\
\hline Hypercapnic & 3 & $87 / 89$ & 23 & 0.27 & $-0.56[-1.85,0.74]$ & $0.84 / 0.4$ \\
\hline Hypoxemic & 3 & $63 / 96$ & 65 & 0.06 & $0.58[-3.52,4.69]$ & $0.28 / 0.78$ \\
\hline
\end{tabular}


Table 5 Subgroup analysis - the effect on secondary outcomes (Continued)

\begin{tabular}{|c|c|c|c|c|c|c|}
\hline \multicolumn{7}{|c|}{ Ventilation mode in the experimental group } \\
\hline CPAP & 1 & $11 / 11$ & NA & NA & $6.00[-0.08,12.08]$ & $1.93 / 0.05$ \\
\hline PSV & 5 & $139 / 174$ & 0 & 0.44 & $-0.81[-1.92,0.30]$ & $1.42 / 0.15$ \\
\hline \multicolumn{7}{|l|}{ Study design } \\
\hline Case-control trial & 4 & $96 / 129$ & 57 & 0.07 & $0.07[-1.45,1.60]$ & $0.1 / 0.92$ \\
\hline $\mathrm{RCT}$ & 2 & $54 / 56$ & 0 & 0.98 & $-1.29[-2.86,0.28]$ & $1.61 / 0.11$ \\
\hline \multicolumn{7}{|c|}{ Interfaces used in the control group } \\
\hline Facial mask & 5 & $111 / 144$ & 51 & 0.08 & $-0.49[-1.66,0.69]$ & $0.81 / 0.42$ \\
\hline Oronasal mask & 1 & $39 / 41$ & NA & NA & $-1.26[-4.28,1.76]$ & $0.82 / 0.41$ \\
\hline
\end{tabular}

$\mathrm{H} / \mathrm{C}$ helmet/control, $M D$ mean difference, $\mathrm{Cl}$ confidence interval, $I C U$ intensive care unit, $A R F$ acute respiratory failure, $C P A P$ continuous positive airway pressure, $P S V$ pressure support ventilation, high quality randomized controlled trial, $\mathrm{PaO}_{2} / \mathrm{FiO}_{2}$ the ratio of the partial pressure of oxygen in arterial blood to the inspired oxygen fraction, $\mathrm{pH}$ potential of hydrogen, $\mathrm{PaCO}_{2}$ partial pressure of carbon dioxide, $\mathrm{NA}$ not applicable

forebode NIV failure and life-threatening consequences $[14,48-50]$. It should be noted that this finding did not mean NIV with a helmet had no effect on the mortality of patients with hypercapnic ARF, since only two studies with small sample sizes had reported this variable in this meta-analysis [20,30]; this question warrant further investigation.

The pooled effect indicated that NIV through a helmet decreased complications and intubation rate dramatically. The helmet was a transparent plastic hood, which did not come into contact with the patient's face, especially the nose bridge and did not cause skin lesions [13]. With this device, air leaks were localized around the neck, which prevented eye irritation and conjunctivitis. The fixation system was not as complicated as the traditional mask. A simplified fixation system should carry a lower risk of cutaneous lesions. The new-generation helmet, characterized by an annular openable ring placed underneath an inflatable cushion, further reduced discomfort and axillary skin lesions caused by padded armpit braces in a standard helmet, so complications might only be confined to the neck [51]. Fewer complications aided the patients' adherence to the NIV and increased the success rate although the effect on reducing complications was mainly observed in observational studies and larger RCTs are still needed to confirm the results. In addition, the use of specific ventilator settings with the fastest pressurization rate, higher inspiratory and expiratory pressures could improve patient ventilator interaction $[52,53]$. All of these key issues prevented some patients from intubation.

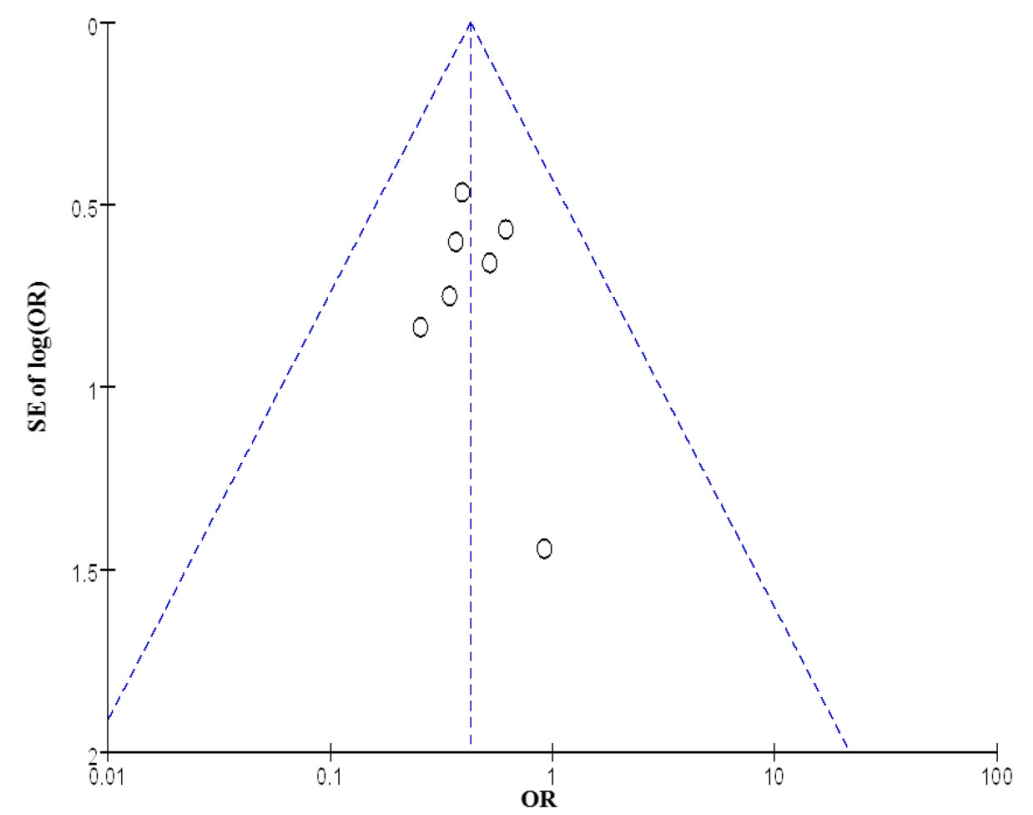

Fig. 4 Funnel plots to assess publication bias regarding the effect of NIV with a helmet on hospital mortality. SE standard error, OR odds ratio 
Our analysis informed that NIV via a helmet was as effective as existing masks in gas exchange although respiratory rates, reflecting the degree of dyspnea to a certain extent, did not decrease noticeably. NIV with a helmet could improve oxygenation by delivering high oxygen concentration, unloading respiratory muscles, recruiting alveoli and increasing functional lung volumes, which was no different from NIV with other interfaces or invasive mechanical ventilation [54]. Moreover, the helmet further reduced leaks in contrast with masks. After all, the aim of introducing the helmet, still a noninvasive interface, was to reduce complications and increase patient comfort, to achieve better use of NIV and improve the prognosis, not just to improve gas exchange further. In theory, the helmet predisposed to $\mathrm{CO}_{2}$ rebreathing, meanwhile the $\mathrm{CO}_{2}$ concentration within the interface depended on the patient's $\mathrm{CO}_{2}$ production and could be minimized by specific settings including high fresh gas flow or higher inspiratory pressure [55-57]. NIV through a helmet might take a longer time to achieve the target level of pressure support due to its larger inner volume. At a lower level of pressure support, the helmet might not decrease the work of breathing and has a restricted effect on respiratory rate.

In the past three decades, NIV played a critical role in the treatment of ARF, especially using CPAP and PSV. From a physiological rationale level, PSV could provide more benefit than CPAP. Regrettably, PSV has not been found to offer any advantage in terms of intubation or mortality [58]. As shown in the subgroup analysis by ventilation mode, both CPAP and PSV with a helmet could reduce the mortality and intubation rate, although $\mathrm{PaCO}_{2}$ decreased mainly in the subgroup with PSV, and improve prognosis. This result was similar with the findings in patients with cardiogenic pulmonary edema [58].

Several limitations should be considered when interpreting our findings. First, because of the paucity of studies in this novel strategy, both RCTs and case-control trials were included. Fortunately, the results were substantially confirmed by pooled RCTs or case-control trials separately with low heterogeneity among the studies. Second, patients recruited in the included studies suffered from hypercapnic or hypoxemic ARF and were not highly consistent with each other. Third, the ventilation characteristics were not homogeneous, some were in CPAP mode, others in PSV, and the interface in the control group involved facial, nasal, oronasal and Venturi masks. Fourth, high heterogeneity existed across the studies for the variable $\mathrm{PaCO}_{2}\left(\mathrm{I}^{2}\right.$ equal to $72 \%$ ), this could be partly explained by the ARF type. In addition, publication bias might exist measuring by Begg's and Egger's test, but the final results were credible and steady tested by the trim and fill method, which tend to be more efficient when limited studies are included in a metaanalysis [59]. Finally, all of the included RCTs had high risk of performance bias attributed to the dramatic difference between a helmet and mask, which made it impossible for participants and personnel blinding to the interface and might influence the outcomes in a certain extent, we suggest that more attention should be paid to this key issue in future researches.

\section{Conclusions}

In conclusion, this meta-analysis indicated NIV with a helmet improved the prognosis, reduced the requirement of intubation and complications. The helmet was as effective as the mask in gas exchange despite no additional advantage. It should be noted that there is not sufficient scientific evidence to recommend it in designated patients due to the limited number of trials available. Large RCT studies are still needed to provide more robust evidence.

\section{Key messages}

- NIV with a helmet improved the prognosis, reduced the requirement of intubation and complications. The helmet was as effective as the mask in gas exchange although without any additional advantage.

\section{Acknowledgements}

The study was supported by the Youth Scholar foundation of the First Affiliated Hospital of Zhengzhou University (2014) and the National Nature Science

Foundation of China (Project Number: 81400051). We thank the staff of MECOR Program Level 1 and Level 22016 in Guangzhou for training in clinical research methods (held by ATS).

In addition, we thank Lingling Cui (Epidemiology and Health Statistics, School of Public Health of Zhengzhou University) and Gang Wang (Chinese Cochrane Center, West China Hospital, Sichuan University) for their guidance on statistics.

\section{Authors' contributions}

QL conceived of and designed the study, participated in the literature search, collected data, performed statistical analysis, interpreted the results, and drafted the manuscript. YG participated in the literature search, collecting data, statistical analysis, and helped to draft the manuscript. RC participated in analyzing the data, interpreted the results, and revised the manuscript. ZC participated in study design and coordination, helped to analyze the data, and revised the manuscript. All authors read and approved the final manuscript to be published.

\section{Competing interests}

The authors declare that they have no competing interests.

\section{Author details}

${ }^{1}$ Department of Pulmonary and Critical Care Medicine, the First Affiliated Hospital of Zhengzhou University, 1st Jianshe East Road, Zhengzhou, Henan 450001, People's Republic of China. ${ }^{2}$ Respiratory Mechanics Lab, State Key Laboratory of Respiratory Disease, Guangzhou Institute of Respiratory Disease, First Affiliated Hospital of Guangzhou Medical University, 151st Yanjiang West Road, Guangzhou, Guangdong 510120, People's Republic of China.

Received: 25 April 2016 Accepted: 3 August 2016

Published online: 23 August 2016

\section{References}

1. Lindenauer PK, Stefan MS, Shieh MS, Pekow PS, Rothberg MB, Hill NS. Outcomes associated with invasive and noninvasive ventilation among patients hospitalized with exacerbations of chronic obstructive pulmonary disease. JAMA Intern Med. 2014;174:1982-93. 
2. Masip J, Roque M, Sánchez B, Fernández R, Subirana M, Expósito JA. Noninvasive ventilation in acute cardiogenic pulmonary edema: systematic review and meta-analysis. JAMA. 2005;294:3124-30.

3. Duggal A, Perez P, Golan E, Tremblay L, Sinuff T. Safety and efficacy of noninvasive ventilation in patients with blunt chest trauma: a systematic review. Crit Care. 2013;17:R142.

4. Nava S. Behind a mask: tricks, pitfalls, and prejudices for noninvasive ventilation. Respir Care. 2013;58:1367-76.

5. Esteban A, Ferguson ND, Meade MO, Frutos-Vivar F, Apezteguia C, Brochard L, Raymondos K, Nin N, Hurtado J, Tomicic V, et al. Evolution of mechanical ventilation in response to clinical research. Am J Respir Crit Care Med. 2008;177:170-7.

6. Lee JS, O'Dochartaigh D, MacKenzie M, Hudson D, Couperthwaite S, VillaRoel C, Rowe BH. Factors associated with failure of non-invasive positive pressure ventilation in a critical care helicopter emergency medical service. Prehosp Disaster Med. 2015;30:239-43.

7. Carron M, Freo U, BaHammam AS, Dellweg D, Guarracino F, Cosentini R, Feltracco P, Vianello A, Ori C, Esquinas A. Complications of non-invasive ventilation techniques: a comprehensive qualitative review of randomized trials. Br J Anaesth. 2013;110:896-914.

8. Sferrazza PGF, Di MF, Akoumianaki E, Brochard L. Recent advances in interfaces for non-invasive ventilation: from bench studies to practical issues. Minerva Anestesiol. 2012;78:1146-53.

9. Maruccia M, Ruggieri M, Onesti MG. Facial skin breakdown in patients with non-invasive ventilation devices: report of two cases and indications for treatment and prevention. Int Wound J. 2015;12:451-5.

10. Yamaguti WP, Moderno EV, Yamashita SY, Gomes TG, Maida AL, Kondo CS, de Salles IC, de Brito CM. Treatment-related risk factors for development of skin breakdown in subjects with acute respiratory failure undergoing noninvasive ventilation or CPAP. Respir Care. 2014;59:1530-6.

11. Kramer N, Meyer TJ, Meharg J, Cece RD, Hill NS. Randomized, prospective trial of noninvasive positive pressure ventilation in acute respiratory failure. Am J Respir Crit Care Med. 1995;151:1799-806

12. Lemyze M, Mallat J, Nigeon O, Barrailler S, Pepy F, Gasan G, Vangrunderbeeck N, Grosset P, Tronchon L, Thevenin D. Rescue therapy by switching to total face mask after failure of face mask-delivered noninvasive ventilation in do-not-intubate patients in acute respiratory failure. Crit Care Med. 2013:41:481-8.

13. Pelosi $P$, Severgnini $P$, Aspesi M, Gamberoni C, Chiumello D, Fachinetti $C$, Introzzi L, Antonelli M, Chiaranda M. Non-invasive ventilation delivered by conventional interfaces and helmet in the emergency department. Eur J Emerg Med. 2003;10:79-86.

14. Antonelli M, Conti G, Pelosi P, Gregoretti C, Pennisi MA, Costa R, Severgnin $P$, Chiaranda M, Proietti R. New treatment of acute hypoxemic respiratory failure: noninvasive pressure support ventilation delivered by helmet-a pilot controlled trial. Crit Care Med. 2002;30:602-8.

15. Pisani L, Mega C, Vaschetto R, Bellone A, Scala R, Cosentini R, Musti M, Del FM, Grassi M, Fasano L, et al. Oronasal mask versus helmet in acute hypercapnic respiratory failure. Eur Respir J. 2015;45:691-9.

16. Brambilla AM, Aliberti S, Prina E, Nicoli F, Del FM, Nava S, Ferrari G, Corradi F, Pelosi P, Bignamini A, et al. Helmet CPAP vs. oxygen therapy in severe hypoxemic respiratory failure due to pneumonia. Intensive Care Med. 2014:40:942-9.

17. Principi T, Pantanetti S, Catani F, Elisei D, Gabbanelli V, Pelaia P, Leoni P. Noninvasive continuous positive airway pressure delivered by helmet in hematological malignancy patients with hypoxemic acute respiratory failure. Intensive Care Med. 2004:30:147-50.

18. Barbagallo M, Ortu A, Spadini E, Salvadori A, Ampollini L, Internullo E, Ziegler S, Fanelli G. Prophylactic use of helmet CPAP after pulmonary lobectomy: a prospective randomized controlled study. Respir Care. 2012;57:1418-24.

19. Belenguer-Muncharaz A, Reig-Valero R, Altaba-Tena S, Casero-Roig P, Ferrándiz-Sellés A. Noninvasive mechanical ventilation in severe pneumonia due to H1N1 virus. Med Intensiva. 2011:35:470-7.

20. Antonelli M, Pennisi MA, Pelosi P, Gregoretti C, Squadrone V, Rocco M, Cecchini L, Chiumello D, Severgnini P, Proietti R, et al. Noninvasive positive pressure ventilation using a helmet in patients with acute exacerbation of chronic obstructive pulmonary disease: a feasibility study. Anesthesiology. 2004;100:16-24.

21. Conti G, Cavaliere F, Costa R, Craba A, Catarci S, Festa V, Proietti R, Antonelli M. Noninvasive positive-pressure ventilation with different interfaces in patients with respiratory failure after abdominal surgery: a matched-control study. Respir Care. 2007;52:1463-71.

22. Esquinas RAM, Papadakos PJ, Carron M, Cosentini R, Chiumello D. Clinical review: Helmet and non-invasive mechanical ventilation in critically ill patients. Crit Care. 2013;17:223.

23. Moher D, Shamseer L, Clarke M, Ghersi D, Liberati A, Petticrew M, Shekelle P, Stewart LA. Preferred reporting items for systematic review and metaanalysis protocols (PRISMA-P) 2015 statement. Syst Rev. 2015:4:1.

24. Higgins JP, Thompson SG, Deeks JJ, Altman DG. Measuring inconsistency in meta-analyses. BMJ. 2003;327:557-60.

25. Higgins JPT. Green S. The Cochrane Collaboration: Cochrane Handbook for Systematic Reviews of Interventions; 2011. http://handbook.cochrane.org/.

26. Stang A. Critical evaluation of the Newcastle-Ottawa scale for the assessment of the quality of nonrandomized studies in meta-analyses. Eur J Epidemiol. 2010;25:603-5.

27. Bowden J, Tierney JF, Copas AJ, Burdett S. Quantifying, displaying and accounting for heterogeneity in the meta-analysis of RCTs using standard and generalised Q statistics. BMC Med Res Methodol. 2011;11:41.

28. Higgins JP, Thompson SG. Quantifying heterogeneity in a meta-analysis. Stat Med. 2002;21:1539-58.

29. Ali A, Türkmen A, Turgut N, Altan A, Sari T. Comparison of non-invasive mechanical ventilation with helmet or face mask in patients with acute exacerbation of chronic obstructive pulmonary disease. Tuberk Toraks. 2011;59:146-52

30. Özlem CG, Ali A, Fatma U, Mehtap T, Saziye. Comparison of helmet and facial mask during noninvasive ventilation in patients with acute exacerbation of chronic obstructive pulmonary disease: a randomized controlled study. Turk J Med Sci. 2015;45:600-6.

31. Antonaglia V, Ferluga M, Molino R, Lucangelo U, Peratoner A, RomanPognuz E, De Simoni L, Zin WA. Comparison of noninvasive ventilation by sequential use of mask and helmet versus mask in acute exacerbation of chronic obstructive pulmonary disease: a preliminary study. Respiration. 2011;82:148-54

32. Patel BK, Wolfe KS, Pohlman AS, Hall JB, Kress JP. Effect of noninvasive ventilation delivered by helmet vs face mask on the rate of endotracheal intubation in patients with acute respiratory distress syndrome: a randomized clinical trial. JAMA. 2016;315:2435-41.

33. Tonnelier JM, Prat G, Nowak E, Goetghebeur D, Renault A, Boles JM, L'her E. Noninvasive continuous positive airway pressure ventilation using a new helmet interface: a case-control prospective pilot study. Intensive Care Med. 2003;29:2077-80.

34. Rocco M, Dell'Utri D, Morelli A, Spadetta G, Conti G, Antonelli M, Pietropaoli P. Noninvasive ventilation by helmet or face mask in immunocompromised patients: a case-control study. Chest. 2004;126:1508-15.

35. Potts JM. Noninvasive positive pressure ventilation: effect on mortality in acute cardiogenic pulmonary edema: a pragmatic meta-analysis. Pol Arch Med Wewn. 2009:119:349-53.

36. Lemiale V, Resche-Rigon M, Azoulay E. Early non-invasive ventilation for acute respiratory failure in immunocompromised patients (IVNIctus): study protocol for a multicenter randomized controlled trial. Trials. 2014;15:372.

37. Johnson CS, Frei CR, Metersky ML, Anzueto AR, Mortensen EM. Non-invasive mechanical ventilation and mortality in elderly immunocompromised patients hospitalized with pneumonia: a retrospective cohort study. BMC Pulm Med. 2014;14:7.

38. Schallom M, Cracchiolo L, Falker A, Foster J, Hager J, Morehouse T, Watts P, Weems $L$, Kollef M. Pressure ulcer incidence in patients wearing nasal-oral versus full-face noninvasive ventilation masks. Am J Crit Care. 2015:24:349-56. quiz 357

39. Scandroglio M, Piccolo U, Mazzone E, Agrati P, Aspesi M, Gamberoni C, Severgnini P, Di SR, Chiumello D, Minoja G, et al. Use and nursing of the helmet in delivering non invasive ventilation. Minerva Anestesiol. 2002;68:475-80.

40. Liu J, Duan J, Bai L, Zhou L. Noninvasive ventilation intolerance: characteristics, predictors, and outcomes. Respir Care. 2016;61:277-84.

41. Silva RM, Timenetsky KT, Neves RC, Shigemichi LH, Kanda SS, Maekawa C, Silva E, Eid RA. Adaptation to different noninvasive ventilation masks in critically ill patients. J Bras Pneumol. 2013;39:469-75.

42. Mehta S, Hill NS. Noninvasive ventilation. Am J Respir Crit Care Med. 2001:163:540-77.

43. Nicolini A, Ferraioli G, Ferrari-Bravo M, Barlascini C, Santo M, Ferrera L. Early non-invasive ventilation treatment for respiratory failure due to severe community-acquired pneumonia. Clin Respir J. 2016;10:98-103. 
44. Navalesi P, Pollini A. Acute respiratory failure in patients with severe community-acquired pneumonia: a prospective randomized evaluation of noninvasive ventilation. Am J Respir Crit Care Med. 2000;162:761-2.

45. Murad A, Li PZ, Dial S, Shahin J. The role of noninvasive positive pressure ventilation in community-acquired pneumonia. J Crit Care. 2015;30:49-54.

46. Keenan SP, Mehta S. Noninvasive ventilation for patients presenting with acute respiratory failure: the randomized controlled trials. Respir Care. 2009;54:116-26.

47. Conti G, Antonelli M, Rocco M. Noninvasive ventilation in intensive care unit patients. Monaldi Arch Chest Dis. 2000;55:50-3.

48. Schettino G, Altobelli N, Kacmarek RM. Noninvasive positive-pressure ventilation in acute respiratory failure outside clinical trials: experience at the Massachusetts General Hospital. Crit Care Med. 2008;36:441-7.

49. Carrillo A, Gonzalez-Diaz G, Ferrer M, Martinez-Quintana ME, Lopez-Martinez A, Llamas N, Alcazar M, Torres A. Non-invasive ventilation in communityacquired pneumonia and severe acute respiratory failure. Intensive Care Med. 2012;38:458-66.

50. Carron M, Freo U, Zorzi M, Ori C. Predictors of failure of noninvasive ventilation in patients with severe community-acquired pneumonia. J Crit Care. 2010;25:540. e9-14.

51. Olivieri C, Costa R, Spinazzola G, Ferrone G, Longhini F, Cammarota G, Conti $\mathrm{G}$, Navalesi P. Bench comparative evaluation of a new generation and standard helmet for delivering non-invasive ventilation. Intensive Care Med. 2013;39:734-8

52. Vargas F, Thille A, Lyazidi A, Campo FR, Brochard L. Helmet with specific settings versus facemask for noninvasive ventilation. Crit Care Med. 2009;37:1921-8

53. Olivieri C, Longhini F, Cena T, Cammarota G, Vaschetto R, Messina A, Berni P, Magnani C, Della CF, Navalesi P. New versus conventional helmet for delivering noninvasive ventilation: a physiologic, crossover randomized study in critically ill patients. Anesthesiology. 2016;124:101-8.

54. Wysocki M, Antonelli M. Noninvasive mechanical ventilation in acute hypoxaemic respiratory failure. Eur Respir J. 2001;18:209-20.

55. Taccone P, Hess D, Caironi P, Bigatello LM. Continuous positive airway pressure delivered with a "helmet": effects on carbon dioxide rebreathing. Crit Care Med. 2004;32:2090-6.

56. Mojoli F, lotti GA, Gerletti M, Lucarini C, Braschi A. Carbon dioxide rebreathing during non-invasive ventilation delivered by helmet: a bench study. Intensive Care Med. 2008:34:1454-60.

57. Patroniti N, Foti G, Manfio A, Coppo A, Bellani G, Pesenti A. Head helmet versus face mask for non-invasive continuous positive airway pressure: a physiological study. Intensive Care Med. 2003;29:1680-7.

58. Nouira S, Boukef R, Bouida W, Kerkeni W, Beltaief K, Boubaker H, Boudhib L,

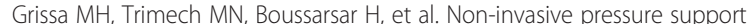
ventilation and CPAP in cardiogenic pulmonary edema: a multicenter randomized study in the emergency department. Intensive Care Med. 2011;37:249-56

59. Tweedie ST. Practical estimates of the effect of publication bias in metaanalysis. Australasian Epidemiologist. 1998;5:14-7.

\section{Submit your next manuscript to BioMed Central and we will help you at every step:}

- We accept pre-submission inquiries

- Our selector tool helps you to find the most relevant journal

- We provide round the clock customer support

- Convenient online submission

- Thorough peer review

- Inclusion in PubMed and all major indexing services

- Maximum visibility for your research

Submit your manuscript at www.biomedcentral.com/submit

) Biomed Central 